Programa de Residência Pedagógica na Licenciatura em Informática: partilhando possibilidades

\title{
DIÁLOGO ENTRE ENSINO DE INFORMÁTICA E ENSINO DE HISTÓRIA: PRÁXIS INTERDISCIPLINAR E INTEGRADORA
}

Franciele C. da Fonseca ${ }^{1}$, Maryanna D. de Medeiros ${ }^{2}$, Kleber Kroll de Azevedo Silva ${ }^{3}$

PALAVRAS-CHAVE

Informática;

História;

Interdisciplinaridade;

Prática Integradora.

\section{RESUMO}

Os dispositivos da era digital estão presentes na maioria das escolas públicas. Porém, a sua inserção qualitativa para os atores escolares ainda é um desafio. A informática é vista muitas vezes como ferramenta, e não como disciplina. A partir dessa problemática, este capítulo tem por objetivo apresentar a importância da informática no contexto interdisciplinar a partir das experiências vividas na Escola Estadual Poeta Renato Caldas, por meio do Programa de Residência Pedagógica, com base em alguns conceitos sobre currículo e formação de professores. Essas experiências foram realizadas na disciplina de História, integrando os conceitos de informática. Os resultados apontam que o caminho para a implementação da informática como disciplina obrigatória ainda é longo. Porém, mostram, por outro lado, que com criatividade e empenho as escolas conseguem inseri-la na sala de aula, motivando os alunos e difundindo os conteúdos significativamente.

\section{INTRODUÇÃO}

No Brasil, a Lei de Diretrizes e Bases da Educação Nacional - LDB n 9.394/1996 - prevê que as escolas públicas trabalhem em tempo integral e estas precisam estar preparadas para receber os alunos por um período maior de tempo. Com carga horária maior, os alunos podem desenvolver várias atividades durante o dia, sem permitir que a quantidade excessiva de atividades resulte em cansaço.

Uma das atividades propostas para esse aumento de carga horária é incluir as Tecnologias de Informação e Comunicação (TIC's) na sala de aula. Mas, como inserir essas tecnologias se, de acordo com a Base Nacional Comum Curricular (BNCC), a informática básica, que é uma disciplina inicial, não está prevista na matriz curricular das escolas como disciplina obrigatória, mas, sim, como ferramenta para auxiliar na sala de aula outras disciplinas?

\footnotetext{
${ }^{1}$ Graduando do Curso Superior de Licenciatura em Informática no Instituto Federal de Educação, Ciência e Tecnologia do Rio Grande do Norte (IFRN) - Campus Ipanguaçu. E-mail: fran.bielly@hotmail.com

2 Graduando do Curso Superior de Licenciatura em Informática no Instituto Federal de Educação, Ciência e Tecnologia do Rio Grande do Norte (IFRN) - Campus Ipanguaçu. E-mail: marydaurea123@gmail.com

3 Professor Efetivo do Instituto Federal de Educação, Ciência e Tecnologia do Rio Grande do Norte (IFRN) - Campus Ipanguaçu. Mestre, Universidade do Estado do Rio Grande do Norte - UERN. Email: kleber.kroll@ifrn.edu.br
} 


\section{Franciele Cunha, Maryanna Daúrea E Kleber Kroll}

Com base nesse questionamento, a ideia proposta era trabalhar, por meio da interdisciplinaridade nos componentes curriculares de Informática Básica e História, conceitos básicos para a elaboração de pesquisas e a utilização de aplicativos sobre os conteúdos desenvolvidos pelos professores.

Hoje em dia, os alunos não gostam de permanecer sentados só ouvindo o professor falar sobre determinado assunto, então inserir as TIC's nas aulas possibilita despertar o interesse do aluno e desenvolver a aprendizagem deste, tornando a aula mais atrativa.

O objetivo desse capítulo é evidenciar a importância da informática no contexto interdisciplinar, a partir das experiências vividas na Escola Estadual Poeta Renato Caldas, por meio do Programa de Residência Pedagógica.

A motivação para a escrita deste capítulo é mostrar como a informática é capaz de se comportar como disciplina e não somente como ferramenta de auxílio, pois a maioria das escolas públicas não inclui em sua matriz curricular a disciplina inicial de Informática, muitas vezes por não ter uma infraestrutura tecnológica adequada e nem profissionais capacitados para que as aulas sejam ministradas. Os recursos tecnológicos digitais, na maioria das vezes, são inexistentes ou estão em situação precária, o que torna mais difícil o ensino da informática.

\section{DESENVOLVIMENTO}

O avanço das tecnologias vem mostrando mudanças significativas para a sociedade no âmbito educacional. A informática como instrumento de aprendizagem se torna um facilitador no processo do ensino. De acordo com Fróes (1994, p. 18, apud Lacerda, 2012, p. 3):

\footnotetext{
Os recursos atuais da tecnologia, os novos meios digitais: a multimídia, a Internet, a telemática, trazem novas formas de ler, de escrever, e, portanto, de pensar e agir. O simples uso de um editor de textos mostra como alguém pode registrar seu pensamento de forma distinta daquela do texto manuscrito ou mesmo datilografado, provocando no indivíduo uma forma diferente de ler e interpretar o que escreve, forma esta que se associa, ora como causa, ora como consequência, a um pensar diferente.
}

Assim, percebe-se como a informática é importante para a sociedade e como ela pode ajudar o aluno a se desenvolver em determinadas disciplinas, uma vez que ela não veio para substituir o professor e, sim, auxiliá-lo em determinadas tarefas em sala de aula. Mas, para que isso aconteça, a escola precisa ter um espaço adequado e um profissional qualificado.

O capítulo mostra a possibilidade de inserir as tecnologias no contexto escolar, por meio da interdisciplinaridade, tendo como consequência a inserção da computação no ambiente escolar, identificando as dificuldades dos alunos em relação à informática e relacionando as TIC's junto a outras disciplinas. 


\title{
CURRÍCULO NA EDUCAÇÃO BÁSICA
}

Já vem sendo adotado em muitas escolas do país o currículo em tempo integral, visando possibilitar aos estudantes ampliação nos conteúdos curriculares para que tenham uma formação básica de qualidade. A Lei de Diretrizes e Bases da Educação Nacional e a BNCC designam parâmetros a serem seguidos para se obter ensino igualitário em todas as regiões, buscando sempre alcançar o desempenho satisfatório dos alunos.

A esse respeito, Mello (2014, p. 1) afirma que:

\begin{abstract}
Currículo é tudo aquilo que uma sociedade considera necessário que os alunos aprendam ao longo de sua escolaridade. Como quase todos os temas educacionais, as decisões sobre currículo envolvem diferentes concepções de mundo, de sociedade e, principalmente, diferentes teorias sobre o que é o conhecimento, como é produzido e distribuído, qual seu papel nos destinos humanos.
\end{abstract}

Pode-se dizer, então, que o currículo é um conjunto de ações desenvolvidas por professores e gestores da escola, a fim de traçar metas e objetivos que deverão ser trabalhadas durante o ano letivo com os alunos. Complementando a fala dessa autora, Veiga (2002 p. 7 apud Medeiros; et al, [20-?] ) assevera:

O currículo é uma parte importante da organização escolar e faz parte do projeto-político-pedagógico de cada escola. Por isso, ele deve ser pensado e refletido pelos sujeitos em interação que têm um mesmo objetivo e a opção por um referencial teórico que o sustente.

De acordo com o documento Síntese das Diretrizes Curriculares Nacionais para a Educação Básica (BRASIL, 2010), o currículo da BNCC-Ensino Fundamental deve abranger, obrigatoriamente, o estudo da Língua Portuguesa e da Matemática, o conhecimento do mundo físico e natural e da realidade social e política, especialmente a do Brasil, bem como o ensino da Arte, a Educação Física e o Ensino Religioso.

Os componentes curriculares obrigatórios do Ensino Fundamental serão assim organizados em relação às seguintes áreas de conhecimento:

I - Linguagens:

a) Língua Portuguesa;

b) Língua materna, para populações indígenas;

c) Língua estrangeira moderna;

d) Arte;

e) Educação Física;

II - Matemática;

III - Ciências da Natureza;

IV - Ciências Humanas:

a) História; 
b) Geografia;

V - Ensino Religioso.

Muitas escolas municipais e estaduais não adotam no seu currículo o ensino da informática. Ela entra como disciplina obrigatória apenas no ensino técnico. De acordo com a BNCC, a informática é vista apenas como ferramenta capaz de auxiliar o professor em sala de aula.

Sabendo da realidade dessas escolas, trabalhar a informática em sala de aula é algo desafiador. Como fazer para que os alunos se sintam motivados e não deixem o computador distraí-los? Qual metodologia utilizar para desenvolver a interdisciplinaridade entre a informática e a disciplina trabalhada pelo professor em sala? Alguns professores acreditam que a informática pode atrapalhar as aulas de alguma forma, já outros acreditam que a informática pode ser trabalhada lado a lado com as demais disciplinas, deixando a aula mais lúdica.

De acordo com Timboíba et al (2011, apud Bessa et al, [20-?]), "com a desmotivação das crianças na escola, faz-se necessário aproveitar esta oportunidade e descobrir novas formas de proporcionar uma aprendizagem que desperte o interesse e o prazer em aprender". Diante dessa afirmação, podemos perceber que a informática aliada a outras disciplinas pode aumentar o interesse do aluno pelo conteúdo que está sendo trabalhado.

A Escola Estadual Poeta Renato Caldas, localizada no município de Assu/RN, escola-campo deste estudo, utiliza como base para o desenvolvimento de sua ação educativa o Projeto Político Pedagógico (PPP) construído em 2017. Esse documento encontra-se, no momento, em fase de revisão para que se adequar às regras, normas e competências sugeridas pela BNCC, o que não é uma tarefa simples, embora a escola venha inserindo na sua rotina essa discussão.

Essa escola, mesmo não tendo um documento que comprove sua integração com a BNCC, já cumpre algumas delas, por exemplo: “compreender, utilizar e criar tecnologias digitais de informação e comunicação de forma crítica, significativa, reflexiva e ética nas diversas práticas sociais (incluindo as escolares) para se comunicar, acessar e disseminar informações, produzir conhecimentos, resolver problemas e exercer protagonismo e autoria na vida pessoal e coletiva" (BRASIL, 2017).

\section{FORMAÇÃO DOCENTE}

Desde a década de 1990, no Brasil, vem se estudando formas de inclusão da informática como disciplina no currículo escolar e não só como um ponto de apoio para as disciplinas já implantadas. Isso se deve ao avanço tecnológico, ao processo de globalização e a utilização, em países mais desenvolvidos, da informática como componente curricular. Não sem razão, as universidades brasileiras, a partir de 1997, começaram a oferta de cursos para profissionalizar docentes na área de informática.

Muitas escolas hoje em dia já conseguiram seus laboratórios de informática para que haja a inclusão digital. Só que o que podemos perceber em muitas delas é que, os profissionais que estão dando suporte nesses laboratórios não são licenciados da área de informática. É de suma importância se ter nesses ambientes, pessoas licenciadas e qualificadas. 
A formação dos licenciados em diversas áreas é um outro aspecto a ser destacado. A Lei n 9.394/1996, em seu artigo 62, preceitua que:

Art. 62. A formação de docentes para atuar na educação básica far-se-á em nível superior, em curso de licenciatura plena, admitida, como formação mínima para o exercício do magistério na educação infantil e nos cinco primeiros anos do ensino fundamental, a oferecida em nível médio, na modalidade normal (BRASIL, 1996, redação dada pela lei no 13.415 , de 2017).

Assim, a formação docente desses profissionais é primordial para um melhor uso e suporte dos alunos, possibilitando oportunidades para esses profissionais que se formaram atuar na sua área.

Na escola Estadual Poeta Renato Caldas, observou-se que ela não possui um profissional habilitado em Licenciatura em Informática para exercer atividades no laboratório. Lá existem profissionais de outras áreas atuando como tutores de informática no laboratório, auxiliando alunos que aparecem para fazer pesquisas.

\title{
EXPERIÊNCIAS NA ESCOLA-CAMPO
}

Para uma melhor compreensão das teorias estudadas nas universidades, os discentes das licenciaturas precisam da prática para sua formação. Para Pimenta (2006, p. 12):

\begin{abstract}
A prática educativa (institucional) é um traço cultural compartilhado e que tem relações com o que acontece em outros âmbitos da sociedade e de suas instituições. Portanto, no estágio dos cursos de formação de professores, compete possibilitar que os futuros professores se apropriem da compreensão dessa complexidade das práticas institucionais e das ações aí praticadas por seus profissionais, como possibilidade de se prepararem para sua inserção profissional. É, pois, uma atividade de conhecimento das práticas institucionais e das ações nelas praticadas.
\end{abstract}

A fim de contribuir com a formação dos futuros professores, o Ministério da Educação (MEC) lançou, em 2017, o Programa de Residência Pedagógica (PRP), o qual tem como finalidade inserir os licenciandos em um contexto educacional real, ou seja, em escolas públicas, onde terão que cumprir uma carga horária de imersão na escola selecionada, denominada escola-campo. Essas escolas passam por uma seleção, assim como os bolsistas/residentes e professores preceptores que atuarão no Programa.

O PRP começou a ser implantado no IFRN, Campus Ipanguaçu, em agosto de 2018, por meio dos cursos de Licenciatura de Informática e de Química. Foram três escolas públicas selecionadas para receber os alunos do curso de Licenciatura em Informática, dentre as quais a Escola Estadual Poeta Renato Caldas, situada na cidade de Assú, a qual tem turmas do Fundamental I e II em tempo integral, e onde atuamos como bolsistas/residentes.

Como já mencionado, a informática não está inserida no currículo escolar da referida escola-campo e como também não há o professor desta área no laboratório de informática da escola, os bolsistas/residentes do curso de Licenciatura em Informática tiveram que planejar a imersão no ambiente escolar de uma forma que 
integrasse a área de informática com as demais disciplinas, demonstrando que essa integração tem um papel importante na construção do saber dos alunos.

Segundo Libâneo (2013, p. 245):

O planejamento é uma tarefa docente que inclui tanto a previsão das atividades didáticas em termos da sua organização e coordenação em face dos objetivos propostos, quanto a sua revisão e adequação no decorrer do processo de ensino. O planejamento é um meio para se programar as ações docentes, mas também um momento de pesquisa e reflexão intimamente ligado à avaliação.

Inicialmente, houve muita dificuldade em relacionar a informática à disciplina de História, para que aquela não ficasse só como um apoio de pesquisa a essa. Buscamos plataformas, sites relacionados à própria disciplina que usassem jogos para trabalhar os conteúdos e o uso de ferramentas para auxiliar nos trabalhos. A escola-campo trabalha em tempo integral e, com isso, não tínhamos como desenvolver trabalhos em turno inverso, pois os alunos estavam em aula.

Levamos, então, para escola-campo a proposta de um minicurso de informática, já que algumas turmas estavam sem professor. A proposta foi bem aceita, porém não foi desenvolvida por muito tempo, pois foram selecionados os professores que faltavam.

Outra dificuldade que encontramos na execução do programa foi a falta de laboratórios em muitas escolas ou, quando possuem, como é o caso da nossa escolacampo, eles não têm manutenção e suporte ou a internet nem sempre está funcionando, dificultando o trabalho planejado. Uma forma para tentar minimizar a falta de aulas na área seria a computação desplugada.

A computação desplugada trata de um conjunto de atividades que envolvem jogos e exercícios físicos, de modo a introduzir o aluno ao pensamento computacional por meio de conceitos como: números binários, redes, algoritmos computacionais e compressão de dados. As atividades praticadas têm como característica principal o lúdico para que haja o desligamento da ideia de que o ensino de computação depende de aparelhos digitais, como também para evitar a distração provocada pelo equipamento eletrônico. (BELL apud BEZERRA; BARBOSA; ALVES; COUTINHO, 2017, p. $623)$.

Também utilizamos o projetor ou a televisão com acesso à internet para passar filmes relacionados aos temas estudados em sala, seguido de trabalhos para fixação do conteúdo.

Um dos maiores desafios encontrados foi em inserir a informática na educação inclusiva, já que a escola também trabalha com inclusão de crianças especiais. A instituição tem dez alunos com deficiência intelectual matriculados, e dois deles participaram das nossas ações. Por isso, adaptamos nossas aulas de modo que eles não se sentissem excluídos e, nesse sentido, contamos com o apoio de uma professora 


\title{
Franciele Cunha, Maryanna Daúrea E Kleber Kroll
}

tutora que os acompanha em todas as aulas e pode nos ajudar na hora de planejar e executar as tarefas.

Houve de início resistência tanto da escola, por não entender direito o que realmente era o PRP e o que iríamos trabalhar lá, como também dos alunos, pois eles pensavam que estávamos ali para cobrar mais e não os ajudar com a sua formação. $\mathrm{O}$ aluno precisa ser motivado para sair da sua zona de conforto e, por isso, também tem resistência para aceitar o novo. Porém, com o passar dos meses, os resultados começaram a fluir e obtivemos mais êxito nas atividades realizadas.

As experiências na escola-campo passaram por duas etapas: a primeira, foi a observação e a segunda, a regência. Alguns dos encontros com os alunos foram para observar como eles se comportavam diante dos assuntos socializados pelo professor, qual conteúdo seria o melhor para ser inserido a informática e quais metodologias utilizar com a turma. Conforme Nérice (1978, p. 284 apud Brighenti; Biavatti; Souza, 2015, p. 3):

\begin{abstract}
A metodologia do ensino pode ser compreendida como um "conjunto de procedimentos didáticos, representados por seus métodos e técnicas de ensino", esse conjunto de métodos são utilizados com o intuito de alcançar objetivos do ensino e de aprendizagem, com a máxima eficácia e, por sua vez, obter o máximo de rendimento.
\end{abstract}

Nesse sentido, Libâneo (2013, p. 19) nos adverte que “[...] uma vez determinadas as unidades didáticas como unidades preferenciais de análise da prática educativa, é preciso buscar suas dimensões para poder analisar as características diferenciais em cada uma das diversas maneiras de ensinar." Ou seja, não se pode trabalhar qualquer conteúdo de informática com a disciplina de História. O conteúdo não pode ser alheio a esta disciplina e nem confundir a cabeça do aluno; precisa ser pensado com calma para que facilite a compreensão e motive o aluno a buscar mais conhecimento.

A segunda etapa consistiu na regência: primeiramente, foi feita uma reunião com o professor da escola-campo para saber quais conteúdos de História estavam sendo trabalhados e, em consequência, analisar em quais deles poderíamos inserir a Informática. Ou seja, fizemos um planejamento da nossa aula, buscando o melhor aproveitamento do aluno. Para Libâneo (2013, p. 245):

O planejamento é uma tarefa docente que inclui tanto a previsão das atividades didáticas em termos da sua organização e coordenação em face dos objetivos propostos, quanto a sua revisão e adequação no decorrer do processo de ensino. O planejamento é um meio para se programar as ações docentes, mas também um momento de pesquisa e reflexão intimamente ligado à avaliação.

O planejamento é fundamental em todos os momentos da carreira docente, até mesmo para os professores mais experientes. $O$ plano de aula foi revisado pelo 


\section{Franciele Cunha, Maryanna Daúrea \& Kleber Kroll}

professor da disciplina, momento em que dialogamos, compartilhamos conhecimento e tiramos dúvidas. Não houve dificuldades nesse ponto, pois o conteúdo da área da Informática a ser ministrado já era de conhecimento das bolsistas/residentes. O conteúdo de História escolhido para ser trabalhar foi a Préhistória.

Logo após o planejamento com o professor veio a regência. Levamos os alunos para o laboratório de informática, passamos as instruções de como seria a aula e executamos o plano de aula. A proposta era trabalhar o conteúdo da Pré-história com a ferramenta de edição de texto, sendo escolhido o software Writer. Os alunos utilizaram a internet para fazer suas respectivas pesquisas e, com o material pesquisado, demos início às formatações básicas como: fonte (fonte, tamanho, estilos), parágrafo (marcações, centralizado ou justificado) e como criar referências dos sites em que pesquisaram. Ao final, os alunos teriam que nos entregar resumos prontos de suas pesquisas.

A ação planejada foi executada com sucesso, sendo todos os conteúdos ministrados no tempo certo e buscando repassá-los de forma correta. Acreditamos que, por se tratar de um conteúdo mais prático, os alunos se interessavam mais em aprender, pois estavam diretamente conectados à ferramenta, e entrar em uma sala na qual os alunos prestam atenção no que é falado pelas bolsistas/residentes é muito gratificante, tanto aprendemos com eles, como eles aprenderam conosco.

No início, a sensação é de apreensão, pois não é tão simples relacionar duas disciplinas diferentes e fazer com que esta interdisciplinaridade seja realizada de forma satisfatória.

\section{CONSIDERAÇÕES FINAIS}

Neste capítulo buscamos realçar a importância da inserção da informática na sala de aula, por meio da interdisciplinaridade, com a disciplina de História, a fim de auxiliar o professor a tornar as aulas lúdicas e assertivas.

Durante o curso de Licenciatura em Informática os alunos estudam diversas disciplinas da área de educação, o que proporciona uma base teórica para assumir uma turma em qualquer escola. Paulo Freire (2013, p. 43) afirma que "só existe ensino quando este resulta num aprendizado em que o aprendiz se tornou capaz de recriar ou refazer o ensinado, ou seja, em que o que foi ensinado foi realmente aprendido pelo aprendiz".

Com o PRP podemos colocar em prática metodologias e conteúdos adquiridos durante o curso, pois nem tudo que se aprende no curso acontece da mesma forma na realidade escolar. Uma das dificuldades foi conseguir ter boa relação com os alunos, alguns não viam sentido em haver residentes na sala, pois achavam que teriam que desenvolver mais atividades.

De acordo com Libânio (2013, p. 274) “a interação professor-aluno é um aspecto fundamental na organização da 'situação didática', tendo em vista alcançar 


\section{Franciele Cunha, Maryanna Daúrea E Kleber Kroll}

os objetivos do processo de ensino: a transmissão e assimilação dos conhecimentos, hábitos e habilidades".

As experiências adquiridas na Escola Estadual Poeta Renato Caldas, por intermédio do PRP, revelaram que a informática pode ser utilizada em sintonia com qualquer componente curricular. Nesse estudo, a relação foi informática com história, por meio da abordagem interdisciplinar, ainda que a informática não esteja inserida como disciplina obrigatória na matriz curricular da escola-campo.

Por meio dessas experiências concluímos que a informática vem mostrando mudanças significativas na educação. A era digital é uma realidade sem volta e, quando seus dispositivos são utilizados corretamente, os conceitos básicos de informática junto com a disciplina de História, ampliam a formação de consciência dos alunos, ajuda no desenvolvimento das inteligências múltiplas, estimula a escrita, a leitura e a lógica, e facilita a produção de conhecimento pelos próprios alunos.

\section{REFERÊNCIAS}

BESSA, Maria Jackeline Rocha; ALVES, Maria Veridiana Franco; BARBOSA, Maria do Socorro Maia Fernandes. A inserção das novas tecnologias no ensino

fundamental: visão dos professores. [20-?]. Disponível em: <http:/ / editorarealize.com.br/revistas/fiped/trabalhos/6aed000af86a084f9cb02641 61e29dd3(1).pdf>. Acesso em: 17 out. 2019.

\section{BRASIL. Base Nacional Comum Curricular: Educação Infantil e Ensino}

Fundamental. Brasília: MEC/Secretaria de Educação Básica, 2017. Disponível em: http://basenacionalcomum.mec.gov.br/images/BNCC_EI_EF_110518_versaofinal_s ite.pdf. Acesso em: 19 out. 2019.

BRASIL. Ministério da Educação. Lei de diretrizes e bases da educação nacional (Lei $\mathrm{n}^{\circ}$ 9.394). Publicada em 20 de dezembro de 1996. Disponível em:

http:// www.planalto.gov.br/ccivil_03/Leis/L9394.htm. Acesso em: 19 out. 2019.

BRASIL. Ministério da Educação. Síntese das diretrizes curriculares nacionais para a educação básica. s. d. Disponivel em:

http://portal.mec.gov.br/index.php?option=com_docman\&view=download\&alias= 32621-cne-sintese-das-diretrizes-curriculares-da-educacao-basica-pdf\&Itemid=30192. Acesso em: 18 out. 2019.

BRIGHENTI, Josiane; BIAVATTI, Vania Tanira; SOUZA, Taciana Rodrigues de. Metodologias de ensino-aprendizagem: abordagem sob a percepção dos alunos. 2015. Disponível em:

<https://periodicos.ufsc.br/index.php/gual/article/view/19834535.2015v8n3p281>. Acesso em: 15 out. 2019. 
FREITAS, Gilmar. et al. Ensino de computação no ensino médio utilizando técnicas de Computação Desplugada: um relato de experiência. In: CONGRESSO SOBRE TECNOLOGIAS NA EDUCAÇÃO, (ctrl+e), 2017, Mamanguape- PB. Anais [...]. Mamanguape, Paraíba, 2017. Disponível em: http:/ /ceur-ws.org/Vol-1877/. Acesso em: 18 jul. 2018.

FREIRE, Paulo. Pedagogia da autonomia: saberes necessários à prática educativa.43. ed., São Paulo: Paz e Terra, 2011.

LACERDA, Morgana. Informática como disciplina obrigatória na educação básica. 2012. Disponível em:

<https:/ / www.google.com/url?sa=t\&rct=j\&q=\&esrc=s\&source=web\&cd=9\&cad=rja \&uact=8\&ved=2ahUKEwiWnO2i96XlAhVFHLkGHTITAIQQFjAIegQIAxAC\&url=ht tp $\% 3 \mathrm{~A} \% 2 \mathrm{~F} \% 2 \mathrm{Fwww}$.periodicos.letras.ufmg.br\%2Findex.php $\% 2 \mathrm{Fanais} \_$linguagem_t ecnologia \%2Farticle\%2Fdownload\%2F1882\%2F3547\&usg=AOvVaw2dTYd755EnX9j ZYwoppKNX>. Acesso em: 15 out. 2019.

LIBÂNEO, José Carlos. Didática. 2. ed. São Paulo: Cortez, 2013.

MEDEIROS, Aldenisa de Souza et al. Currículo formal: vivência e experiência no cotidiano escolar. [20-?]. Disponível em:

<http://editorarealize.com.br/revistas/fiped/trabalhos/Trabalho_Comunicacao_or al_idinscrito_1170_b33cc416c59b481c382debfc646b0ad6.pdf>. Acesso em: 18 out. 2019.

MELLO, Guiomar Namo de. Currículo da educação básica no Brasil: concepções e políticas. 2014. Disponível em: <http://movimentopelabase.org.br/wpcontent/uploads/2015/09/guiomar_pesquisa.pdf>. Acesso em: 22 out. 2019.

PIMENTA, Selma Garrido; LIMA, Maria Socorro Lucena. Estágio e docência: diferentes concepções. 2006. Disponível em: <https:/ / www.revistas.ufg.br/poiesis/article/download/10542/7012/>. Acesso em: 19 out. 2019. 